\title{
The study of the process of alkaline precipitation purification of solutions from silicon macroscales in the ammonium-fluoride processing of beryllium-containing materials
}

\author{
Alexander Dyachenko ${ }^{1}$, Roman Kraydenko ${ }^{1}$, Margarita Lesnikova ${ }^{1}$, Lev Malyutin ${ }^{1}$ and \\ Ilya Petlin $^{1}$ \\ ${ }^{1}$ Tomsk Polytechnic University, Lenin av. 30, Tomsk, 634050, Russia
}

\begin{abstract}
The ammonium-fluoride method of beryllium materials processing is examined. An analysis of the existing sulfuric-acid and fluoride processing scheme of beryllium-containing concentrates processing is described; advantages of the proposed ammonium-fluoride scheme and possible problems that may occur when testing a new technique are discussed. Studies on determining the effect of silicon macroscales on the behavior of beryllium in fluoride solutions at an increased $\mathrm{pH}$, as well as on establishing the distribution of beryllium and silicon by phases in laboratory testing of the technology on model mixtures, are described. As a result of the studies, it is found that precipitation purification of solutions from silicon with a solution of ammonia is possible at a temperature of $20-25^{\circ} \mathrm{C}$. The paper presents data on the effect of an excessive concentration of ion-fluoride in a solution on the $\mathrm{pH}$ level of silicon precipitation; and on the hydrolysis degree of beryllium and silicon during the precipitation.
\end{abstract}

\section{Introduction}

Beryllium in nature mainly represented about 30 minerals, the most important of them are: beryl, chrysoberyl, behoit, bertrandite, phenacite [1-3]. The volume of metallic beryllium production amounts to nearly 300 tons/year. The main source of beryllium is a bertranditephenacite concentrate which is produced using methods of flotation from the berylliumfluorite-containing ore; the concentrate from the Ermakovskiy deposit, which has been used for following researches, contains up to $4 \%$ of beryllium (Table 1) [4]. 
Table 1. Chemical composition of phenacite concentrate

\begin{tabular}{llllll}
\hline Substance & $\mathrm{Be}$ & $\mathrm{SiO}_{2}$ & $\mathrm{CaF}_{2}$ & $\mathrm{~F}$ & $\mathrm{Al}_{2} \mathrm{O}_{3} ; \mathrm{Fe}_{2} \mathrm{O}_{3} ; \mathrm{CaO}$ \\
\hline Content, $\%$ & 4 & 29 & 20 & 5 & 40 \\
\hline
\end{tabular}

To date, two ways of hydrometallurgical processing of beryllium concentrates have been designed and developed: sulfuric-acid and fluoride (Table 2) [2].

Table 2. Description of existing methods of hydrometallurgical processing of beryllium concentrates

\begin{tabular}{|c|c|c|}
\hline \multirow{2}{*}{ Parameters } & \multicolumn{2}{|l|}{ Processing method } \\
\hline & Sulfuric-acid & Fluoride \\
\hline 1 & 2 & 3 \\
\hline Basic reagents & $\begin{array}{l}93 \% \text { sulfuric acid, water, } \\
\text { ammonium sulphate, caustic soda, } \\
\text { EDTA, ammonium bifluoride } \\
\text { solution }\end{array}$ & $\begin{array}{l}\text { Sodium hexafluorosilicate, soda } \\
\text { ash, caustic soda, iron sulfate (III), } \\
\text { water, ammonium bifluoride }\end{array}$ \\
\hline
\end{tabular}

Melting in an arc furnace, thermal activation of the concentrate, sulfuric-acid interaction, water Mixing of reagents, briquetting, $\begin{array}{lll}\text { Stages } & \text { leaching of beryllium, sintering, water leaching, alkaline } \\ \text { purification from } \mathrm{Al} \text { and } \mathrm{Fe} \text {, precipitation, production of }\end{array}$ formation and hydrolysis of beryllium hydroxide sodium beryllate, production of beryllium hydroxide

Melting point of the concentrate

\begin{tabular}{|c|c|c|}
\hline $\begin{array}{l}\text { Process } \\
\text { conditions }\end{array}$ & $\begin{array}{l}\text { Melting point of the concentrate } \\
\text { in an arc furnace }-1700{ }^{\circ} \mathrm{C} \text {, heat } \\
\text { treatment }-900-950{ }^{\circ} \mathrm{C} \text {, sulfation } \\
-200{ }^{\circ} \mathrm{C} \text {; } \\
\text { Process duration }-20 \text { hours. }\end{array}$ & $\begin{array}{l}\text { Sintering temperature }-750{ }^{\circ} \mathrm{C} \\
\text { Process duration }-32 \text { hours. }\end{array}$ \\
\hline $\begin{array}{l}\text { Energy } \\
\text { intensity }\end{array}$ & High-energy & High-energy \\
\hline $\begin{array}{l}\text { Environmenta } \\
1 \text { risks }\end{array}$ & $\begin{array}{l}\text { High } \\
\text { Utilization of volatile fluorides } \\
\left(\mathrm{SiF}_{4}, \mathrm{HF}\right) \text {, utilization of ferrous } \\
\text { sulphate solutions }\end{array}$ & $\begin{array}{l}\text { High } \\
\text { Potential emissions of beryllium } \\
\text { compounds during crushing and } \\
\text { grinding }\end{array}$ \\
\hline $\begin{array}{l}\text { Possibility of } \\
\text { reagent } \\
\text { regeneration }\end{array}$ & Absent & Partially in the form of $\left(\mathrm{NH}_{4}\right)_{2} \mathrm{FeF}_{6}$ \\
\hline $\begin{array}{l}\text { The volume of } \\
\text { the liquid } \\
\text { phase in the } \\
\text { process }\end{array}$ & High & Average \\
\hline $\begin{array}{l}\text { Beryllium } \\
\text { recovery, \% }\end{array}$ & 80 & 70 \\
\hline $\begin{array}{l}\text { Commercial } \\
\text { products }\end{array}$ & Beryllium metal, plaster & Beryllium metal \\
\hline
\end{tabular}

Disadvantages of the sulfuric-acid method: huge water consumption; multistage processing; necessity in high-temperature two-stage activation of concentrates; large amount of impurities passes into the target solution in the form of sulphates; necessity to produce intermediate highly-toxic beryllium compounds $\left(\mathrm{Be}(\mathrm{OH})_{2}\right)$.

As compared to the sulfuric-acid scheme, the fluoride processing does not include hightemperature, energy-intensive stages of concentrate activation, and there is a possibility to 
regenerate the fluorinating reagent in the form of ferrous cryolite $\left(\mathrm{Na}_{3} \mathrm{FeF}_{6}\right)$ evolved from mother solutions of sodium fluoride which remained after separation of the amorphous $\mathrm{Be}(\mathrm{OH})_{2}$. Disadvantages of the fluoride method: multistaging of the hydrometallurgical process, costly leaching reagent $-\mathrm{Na}_{2} \mathrm{SiF}_{6}$, high consumption of sodium hexafluorosilicate as a result of its intensive decomposition and volatilization of the produced $\mathrm{SiF}_{4}$ from the reaction zone, necessity in a high-temperature stage of concentrate fluorination, necessity to produce highly toxic beryllium compounds $-\mathrm{Be}(\mathrm{OH})_{2}$.

Today, only the sulfuric-acid method is commonly used in processing of concentrates, because it is more economically viable, environmentally sound, and allows producing a cleaner beryllium hydroxide.

\section{Theory section}

In order to improve the profitability and to reduce the risks at production of beryllium metal, a method of ammonium-fluoride processing of beryllium concentrates is being developed. The method is based on the interaction of the concentrate components with ammonium bifluoride $\left(\mathrm{NH}_{4} \mathrm{HF}_{2}\right)$ at $210{ }^{\circ} \mathrm{C}$, omitting stages of concentrate activation. The main component of the ore concentrate from the Ermakovskiy deposit is fluorite $-\mathrm{CaF}_{2}$, which does not react with ammonium bifluoride and is separated at the filtration stage after water leaching of the sinter. The remaining components of the concentrate come into the following interactions [5-6]:

$$
\begin{gathered}
\mathrm{Be}_{2} \mathrm{SiO}_{4}+7 \mathrm{NH}_{4} \mathrm{HF}_{2} \rightarrow 2\left(\mathrm{NH}_{4}\right)_{2} \mathrm{BeF}_{4}+\left(\mathrm{NH}_{4}\right)_{2} \mathrm{SiF}_{6}+4 \mathrm{H}_{2} \mathrm{O} \uparrow+\mathrm{NH}_{3} \uparrow, \\
\mathrm{Al}_{2} \mathrm{O}_{3}+6 \mathrm{NH}_{4} \mathrm{HF}_{2} \rightarrow 2\left(\mathrm{NH}_{4}\right)_{3} \mathrm{AlF}_{6}+3 \mathrm{H}_{2} \mathrm{O} \uparrow \\
\mathrm{Fe}_{2} \mathrm{O}_{3}+5 \mathrm{NH}_{4} \mathrm{HF}_{2} \rightarrow 2\left(\mathrm{NH}_{4}\right)_{2} \mathrm{FeF}_{5}+3 \mathrm{H}_{2} \mathrm{O} \uparrow+\mathrm{NH}_{3} \uparrow \\
\mathrm{CaO}+\mathrm{NH}_{4} \mathrm{HF}_{2} \rightarrow \mathrm{CaF}_{2}+\mathrm{H}_{2} \mathrm{O} \uparrow+\mathrm{NH}_{3} \uparrow \\
\mathrm{SiO}_{2}+3 \mathrm{NH}_{4} \mathrm{HF}_{2} \rightarrow\left(\mathrm{NH}_{4}\right)_{2} \mathrm{SiF}_{6}+2 \mathrm{H}_{2} \mathrm{O} \uparrow+\mathrm{NH}_{3} \uparrow
\end{gathered}
$$

With further aqueous leaching of the sinter the following compounds go into the solution: beryllium, silicon, partially iron and aluminum, excessive ammonium bifluoride. Fluorides of calcium, partially of aluminum and iron, remain in the insoluble precipitate.

The next stage of the process is the alkaline precipitation purification of the beryllium solution from impurities. Beryllium remains in the solution in the form of $\mathrm{BeF}_{4}{ }^{2-}$ - ion, and impurities (the main impurity is silicon) precipitate as a result of hydrolysis under the following reactions:

$$
\begin{aligned}
&\left(\mathrm{NH}_{4}\right)_{2} \mathrm{FeF}_{5}+3 \mathrm{NH}_{4} \mathrm{OH}=\mathrm{Fe}(\mathrm{OH})_{3} \downarrow+5 \mathrm{NH}_{4} \mathrm{~F} \\
&\left(\mathrm{NH}_{4}\right)_{3} \mathrm{AlF}_{6}+3 \mathrm{NH}_{4} \mathrm{OH}=\mathrm{Al}(\mathrm{OH})_{3} \downarrow+6 \mathrm{NH}_{4} \mathrm{~F} \\
&\left(\mathrm{NH}_{4}\right)_{2} \mathrm{SiF}_{6}+4 \mathrm{NH}_{4} \mathrm{OH}=\mathrm{Si}(\mathrm{OH})_{4} \downarrow+6 \mathrm{NH}_{4} \mathrm{~F}
\end{aligned}
$$

The purified solution $\left(\mathrm{NH}_{4}\right)_{2} \mathrm{BeF}_{4}$, omitting the stage of production of highly toxic $\mathrm{Be}(\mathrm{OH})_{2}$, goes to crystallization. The formed crystals of ammonium fluoroberyllate are subjected to thermal decomposition to produce $\mathrm{BeF}_{2}[5]$.

The aim of this research was the study the influence of silicon macroscales on the behavior of beryllium in fluoride solutions at an increased $\mathrm{pH}$, as well as the establishment of the distribution of beryllium and silicon by phases in laboratory testing of the described ammonium-fluoride technology on model mixtures. 


\section{Material and methods}

The prepared model mixture, consisting of $\mathrm{BeO}$ and $\mathrm{SiO}_{2}$, was combined with ammonium bifluoride taken with a $50 \%$ excess relative to the stoichiometric amount. The load was placed into a laboratory shaft furnace, where the fluorination process of the model mixture took place during 1 hour at a temperature of $210^{\circ} \mathrm{C}$. The produced sinter was crushed and dissolved in $200 \mathrm{ml}$ of water. The sinter dissolved completely. The $\mathrm{pH}$ level of the solution was equal to 3 . A complete dissolution of the fluorinated product demonstrates the importance of the fluorination degree approximately equal to $100 \%$.

Precipitation was carried out with an ammonia solution at room temperature; the $\mathrm{pH}$ value was gradually increased until a white precipitate. The pulp was settled at each $\mathrm{pH}$ unit for 1 hour. Precipitation was observed during the transition of $\mathrm{pH}$ level from 7 to 8 . The produced pulp was filtered, and the clarified solution was brought up to $\mathrm{pH}=9$, the precipitate no longer formed. The precipitate after the filtration was pulped in $100 \mathrm{ml}$ of water; the formed on the filter cake was washed with another $100 \mathrm{ml}$ of water. The washed precipitate was removed together with the filter and transferred to a platinum cup. The precipitate was dried at $150{ }^{\circ} \mathrm{C}$ for 2 hours, then calcined at $700{ }^{\circ} \mathrm{C}$.

Crystallization of $\left(\mathrm{NH}_{4}\right)_{2} \mathrm{BeF}_{4}$ from the filtrate was carried out until a gelatinous mass was obtained. Then, amorphous crystals were dried for 3 hours without heating using an air extraction system. Thermal decomposition of $\left(\mathrm{NH}_{4}\right)_{2} \mathrm{BeF}_{4}$ was carried out at $500{ }^{\circ} \mathrm{C}$ in a platinum cup.

The elemental analysis of liquid and solid samples was carried out using an atomicemission spectrometer with an inductive coupled plasma iCAP 6300 Duo. To dissolve solid samples, the microwave system MARS 6 was used. A scandium solution with a concentration of $100 \mathrm{ppm}$ was used as an internal standard. To calibrate the method, state standard reference samples (GSO) were used: for silicon - GSO 8934-2008, beryllium GSO 7759-2000. In sample preparation the following acids were used: hydrochloric (GOST 14261-77), nitric (GOST 4461-77), and hydrofluoric (TU 2612-007-56853252-2010). The analysis was carried out under the following lines: for beryllium - 234.8; 249.4; $265.0 \mathrm{~nm}$; silicon - 198.8; 251.6; $288.1 \mathrm{~nm}$.

\section{Results and discussion}

As a result of the precipitation purification of beryllium fluoride solutions from silicon macrocsales, more than $21 \%$ of beryllium removes together with a gelatinous precipitate of polysilicon acids. But, during washing of the produced cake with ordinary distilled water it is possible to recover $18.5 \%$ of beryllium into the solution, which indicates the absence of a large-scale hydrolysis of $\mathrm{BeF}_{4}{ }^{2-}$ - ion at $\mathrm{pH}$ equal to 9 and a ratio of a free fluoride-ion to beryllium equal to $\mathrm{Be}: \mathrm{F}=1: 6$. Fluoroberyllate ion in the basic amount is drawn into a jellylike precipitate together with moisture; as a result of alkali hydrolysis $2.7 \%$ of beryllium is precipitated.

Approximately $2 \%$ of silicon remains in the clarified solution at a $\mathrm{pH}$ level equal to 9 .

An incomplete removal of silicon, as well as a very high $\mathrm{pH}$ of silicon hydrolysis $(\mathrm{pH}=7)$, is associated with a large excess of fluoride-ion present in the solution. Part of silicon can be removed in the form of $\left(\mathrm{NH}_{4}\right)_{2} \mathrm{SiF}_{6}$ at the stage of thermal decomposition of $\left(\mathrm{NH}_{4}\right)_{2} \mathrm{BeF}_{4}$ (Fig. 1). 


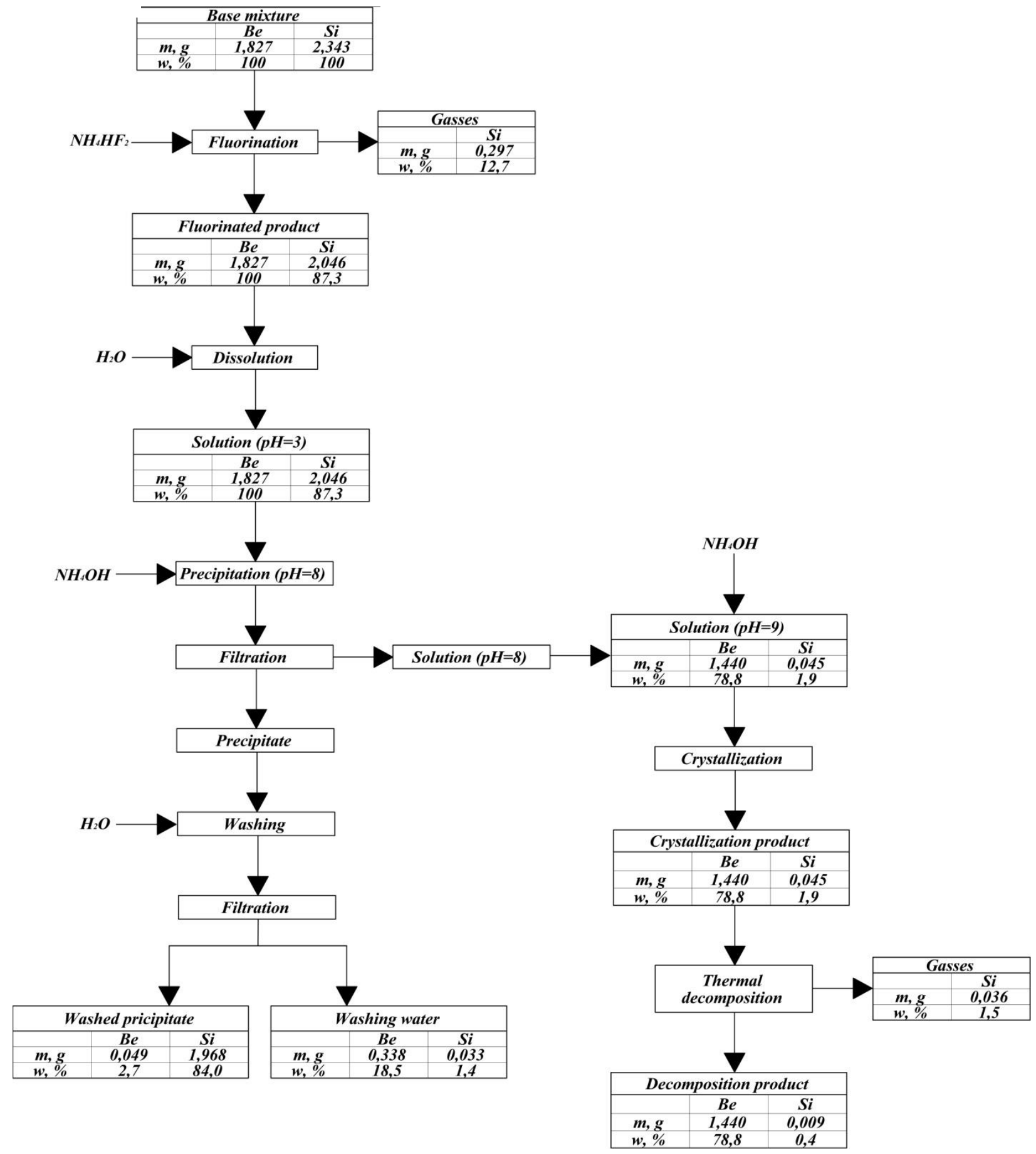

Figure 1. Distribution of beryllium and silicon by phases 


\section{Conclusion}

1. Precipitation purification of beryllium fluoride solutions from silicon macroscales is feasible at room temperature $\left(20-25^{\circ} \mathrm{C}\right)$ and at a ratio $\mathrm{Be}: \mathrm{F}=1: 6$.

2. Co-precipitation of beryllium and silicon was not established. Approximately $18.5 \%$ of beryllium removes together with the precipitate of polysilicic acids in the composition of the adsorbed by the cake moisture. During the purification $2.7 \%$ of beryllium hydrolyzes and precipitates in the form of $\mathrm{Be}(\mathrm{OH})_{2}$.

3. Due to a significant amount of fluoride-ion present in the productive solutions, the $\mathrm{pH}$ of hydrolysis $\mathrm{SiF}_{6}{ }^{2-}$ - ion increases up to 7 .

4. It was impossible to completely remove silicon at the stage of precipitation purification: $1.9 \%$ of silicon remains in the solution of ammonium fluoroberyllate. It is possible to remove the remaining portion of silicon at the stage of thermal decomposition in the form of $\left(\mathrm{NH}_{4}\right)_{2} \mathrm{SiF}_{6}$.

5. The purity of beryllium fluoride produced during the study was $99.7 \%$. The amount of $\mathrm{SiO}_{2}$ in the product was $0.3 \%$.

\section{References}

1. D.D. Thorat, B.M. Tripathi, D. Sathiyamoorthy. Extraction of beryllium from Indian beryl by ammonium hydrofluoride // Hydrometallurgy, 109 (2011). - P. 18-22.

2. E.E. Zaki, Z.H. Ismail, J.A. Daoud, H.F. Aly. Extraction equilibrium of beryllium and aluminium and recovery of beryllium from Egyptian beryl solution using CYANEX 921 // Hydrometallurgy, 80 (2005). - P. 221-231.

3. D.W. White, J. E. Burke. The Metall Beryllium. American Society for Metals, 1955 $-703 \mathrm{p}$.

4. Samoylov V.I, Borsuk A.N. Methods for co-processing of phenacite, bertrandite, and beryl in beryllium hydrometallurgy, Media Alliance, Ust-Kamenogorsk, 2006.

5. V.S. Rimkevich, A.A. Pushkin, A.A. Malovitskii, Yu.N. Dem’yanova, I.V. Girenko. Fluoride processing of non-bauxite ores // Russian Journal of Applied Chemistry. 2009.

$\mathrm{V}$.

82.

№ 1 - P. 6-11.

6. Andreev A.A., Dyachenko A.N., Kraydenko R.I., Russian Journal of Applied Chemistry, 81 (2), (2008), 178-182.

7. Silina G.F., Zarembo Yu.I., Bertina L.E. Beryllium. Chemical technology and metallurgy, Atomizdat, Moscow, 1960. 